\title{
Aneurysm of the Left Portal Branch
}

\author{
Diego Martínez ${ }^{1}$, Maria Teresa Belmonte ${ }^{2}$, Piotr Kosny ${ }^{3}$, Maria Rosario Gómez $^{4}$, Diego Hellìn ${ }^{4}$ \\ ${ }^{1}$ Radiology Department, Hospital Vega Baja, Orihuela, Alicante, Spain \\ ${ }^{2}$ Intensive Care Department, Hospital Vega Baja, Orihuela, Alicante, Spain \\ ${ }^{3}$ Surgery Department, Hospital Vega Baja, Orihuela, Alicante, Spain \\ ${ }^{4}$ Department of Otorhinolaryngology, Hospital General Universitario Reina Sofía, Murcia, Spain
}

\section{Doi: 10.12890/2018_000868- European Journal of Case Reports in Internal Medicine - ( ) EFIM 2018}

Received: 20/02/2018

Accepted: 16/03/2018

Published: 17/04/2018

How to cite this article: Martínez D, Belmonte MT, Kosny P, Gómez MR, Hellìn D. Aneurysm of the left portal branch. EJCRIM 2018;5: doi:10.12890/2018_000868.

Conflicts of Interests: The Authors declare that there are no competing interests.

This article is licensed under a Commons Attribution Non-Commercial 4.0 License

\section{ABSTRACT}

We describe the incidental finding of an aneurysm of the left branch of the portal vein in a patient without liver pathology. The diagnosis was confirmed by Doppler ultrasound.

\section{LEARNING POINTS}

- Portal vein aneurysms are rare but have been described in patients with cirrhosis and portal hypertension.

- In most cases they are stable and do not progress.

- However, they do require follow-up in case serious complications develop.

\section{KEYWORDS}

Portal vein aneurysm, congenital, doppler

\section{INTRODUCTION}

Aneurysms are frequently found in arteries. However, they can also be found in veins, with cases described in the popliteal, jugular and saphenous veins ${ }^{[1]}$. Aneurysms of the portal venous system are rare and in most cases associated with portal hypertension.

\section{CASE REPORT}

A 29-year-old woman with no relevant history, was admitted to our hospital for lower right basal pneumonia. CT with contrast of the thorax revealed a $28 \mathrm{~mm}$ saccular dilatation in the liver at the left portal bifurcation (Fig. 1). Liver ultrasound showed a saccular anechoic image at the exit of the left portal branch, with Doppler imaging showing a yin-yan sign (Fig. 2), compatible with an aneurysm. There were no signs of liver disease or suspicious lesions. Serology was negative for hepatitis and liver function tests were normal.

\section{DISCUSSION}

Aneurysms of the portal venous system are rare with about 170 cases described ${ }^{[1]}$. However, in recent years the number of reports has increased, most likely due to improved imaging techniques.

Aneurysms of the portal system are the most common visceral aneurysms, accounting for $3 \%$ of venous aneurysms ${ }^{[2]}$, with a prevalence of $0.43 \%^{[3]}$. Doppler ultrasonography shows a characteristic yin-yan image. As $20 \%$ of patients have multiple aneurysms ${ }^{[3]}$, CT or MRI of 

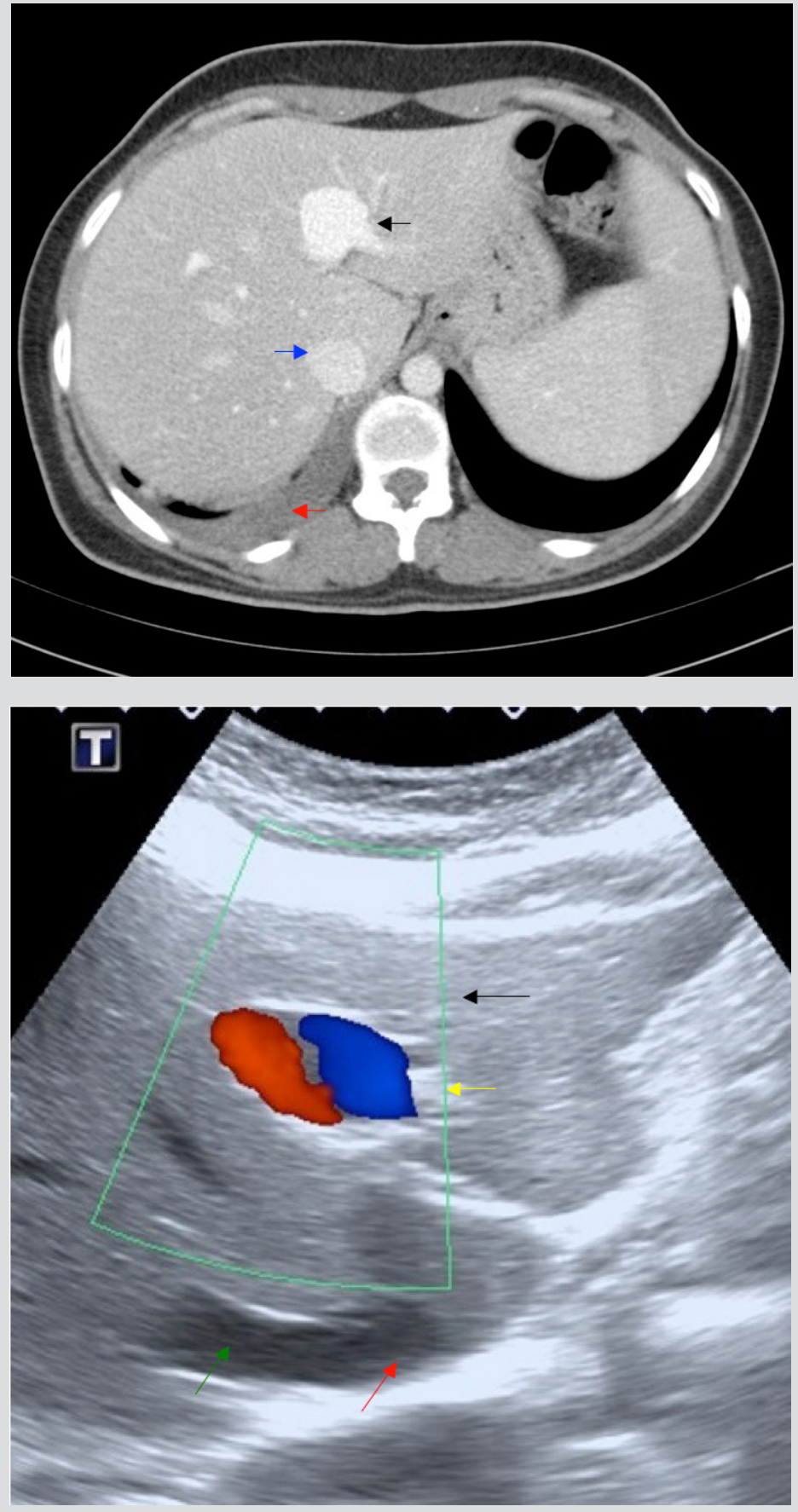

Figure 1. Computed tomography with contrast of the upper sections of the abdomen, showing dilation of the left portal branch (black arrow) with a diameter greater than that of the inferior vena cava (blue arrow). A slight posterior right pleural effusion is seen (red arrow).
Figure 2. Axial section of abdominal ultrasound showing the liver (black arrow). Doppler imaging shows a yin-yan sign at the output of left portal branch compatible with an aneurysm (yellow arrow). The right suprahepatic vein (green arrow) can be seen at its junction with the inferior cava vena (red arrow).

the abdomen should be performed to examine the entire portal system. The most common location is the extrahepatic portal vein at its confluence with the splenic vein and the superior mesenteric vein ${ }^{[2]}$. Extrahepatic aneurysms are more common than intrahepatic aneurysms, with intrahepatic portal vein aneurysms being rare: three cases have been described in the right portal branch and one in the left, although 19 have been described in the umbilical portion of the left portal vein ${ }^{[1]}$.

Extrahepatic portal venous aneurysms range from 2 to $8 \mathrm{~cm}$ in diameter and intrahepatic from 1 to $7 \mathrm{~cm}^{[1]}$. Although diameter varies, the maximum portal vein diameter is generally about $15 \mathrm{~mm}$ but $19 \mathrm{~mm}$ in the cirrhotic liver ${ }^{[3]}$. Thus, a vein with a diameter greater than $20 \mathrm{~mm}$ is considered an extrahepatic portal vein aneurysm ${ }^{[2,4]}$. Respiratory movements should be considered during measurement as the diameter of the extrahepatic portal vein increases with inspiration and decreases with expiration. There is no consensus regarding vein diameter 
indicating an aneurysm in the intrahepatic portal system. In their study of 38 aneurysms of the portal system, Koc et al. ${ }^{[3]}$ considered an aneurysm was indicated if the diameter of the intrahepatic portal system was $9 \mathrm{~mm}$ or more and significantly larger than the rest of same segment of vein.

There are three theories concerning the aetiology of portal venous aneurysms: embryological, wall weakness and acquired. The embryological theory postulates origin in the right vitelline vein. During embryonic development, the left vitelline vein and the distal portion of the right vitelline vein anastomose surrounding the future duodenum. After a complex process, the right vitelline vein forms the portal vein and the superior mesenteric vein, while the left vitelline vein forms the splenic vein. Any disruption of this process could lead to an extrahepatic portal vein aneurysm ${ }^{[4]}$. Failure of obliteration of the right vitelline vein ${ }^{[4]}$ or a variant branching pattern of the portal vein can also cause a portal vein aneurysm. Incomplete regression of the vitelline vein has also been related to aneurysms of the superior mesenteric vein ${ }^{[4]}$.

Four cases of intrauterine portal vein aneurysms have been reported. Díaz et al. ${ }^{[5]}$ describe two of these, but as portal sinus aneurysms. In the fetus, the portal sinus is a prolongation of the umbilical vein and divides into the left portal branches, the venous ductus and the right portal vein. After birth, the portal sinus inverts its flow, being the only vascular segment to do this after birth ${ }^{[5]}$. Thus, the portal sinus and left portal vein are the same structure, with the first name used in the prenatal period and the second in the postnatal period. The change in name is a result of changes in function ${ }^{[5]}$.

Another theory suggests weakness in the venous wall. Koc et al. ${ }^{[3]}$ in his serie of 25 patients describes a young patient with cutis laxa presenting with a portal vein aneurysm, which could have been due to weakness of the venous wall.

A significant number of acquired aneurysms present with portal hypertension and liver cirrhosis ${ }^{[2]}$, although they have also been associated with pancreatitis, trauma and the effects of surgery ${ }^{[2-4]}$. Portal hypertension secondary to chronic liver disease is the most common cause of acquired portal vein aneurysm ${ }^{[2,3]}$.

Most portal venous system aneurysms are asymptomatic or have non-specific symptoms ${ }^{[3]}$. The most frequent symptom is abdominal pain, with $7.3 \%$ of patients reporting gastric bleeding ${ }^{[1]}$. Koc et al. $^{[3]}$ describe thrombosis in five of their 25 patients, also reporting that they had larger aneurysms than asymptomatic patients and a higher frequency of multiple aneurysms. Four cases of aneurysm rupture have been described $^{[1]}$. Other complications are aneurysm growth, portal hypertension, distal embolisms and compressive symptoms ${ }^{[1]}$.

Due to its rarity, the natural evolution of a portal system aneurysm is not completely known. At follow-up, $88 \%$ of patients did not show size progression or complications ${ }^{[1]}$. Congenital portal system aneurysms are usually considered stable and only follow-up is needed ${ }^{[1]}$. However, the evolution of acquired portal venous aneurysms, especially when associated with liver cirrhosis and portal hypertension, is more unpredictable and requires closer follow-up and intervention when complications occur ${ }^{[1,4]}$. Most portal venous system aneurysms do not require treatment, so follow-up is sufficient ${ }^{[2]}$, with conservative treatment and surgery reserved for complications.

\section{REFERENCES}

1. Sfyroeras GS, Antoniou GA, Drakou AA, Karathanos C, Giannoukas AD. Visceral venous aneurysms: clinical presentation, natural history and their management: a systematic review. Eur J Vasc Endovasc Surg 2009;38:498-505.

2. López Machado E, Mallorquín Jiménez F, Medina Benítez A, Ruiz Carazo E, Cubero García M. Aneurysms of the portal venous system: ultrasonography and CT findings. Eur J Radiol 1998;26:210-214.

3. Koc Z, Oguzkurt L, Ulusan S. Portal venous systems aneurysms: imaging, clinical findings, and a possible new etiologic factor. AJR Am J Roentgenol 2007;189:1023-1030.

4. Gallego C, Velasco M, Marcuello P, Tejedor D, De Campo L, Friera A. Congenital and acquired anomalies of the portal venous system. Radiographics 2002;22:141-159.

5. Díaz J, Alonso JA, Frontela C, López-Menéndez M. Aneurisma del seno portal: diagnóstico prenatal. Prog Obstet Ginecol 2013;56:427-431. 